\title{
The Hierarchy of Value Orientations in Kazakhstan as the Basis of National Mentality
}

\section{Lyazzat llimkhanova}

PhD doctoral candidate, Independent Scientist - researcher, Email:lyazzat.ilimkhanova@gmail.com

Mukhan Perlenbetov

Doctor of Psychological Sciences; professor and vice-rector of Kainar University; academician of the Kazakh National Academy of Sciences. Email:phd2014.kz@gmail.com

Saltanat Tazhbayeva

Candidate of Psychological Sciences KazNPU after Abai.

Email: saltanat.tazhbay@mail.ru

Meruert Assylkhanova

Candidate of Pedagogical Scienses KazNPU after Abai. Email:phd2014.kz@gmail.com

Gulmira Topanova

Teacher of Pavlodar State Pedagogical University. Email:gulmira.topan@mail.ru

Zuhra Sadvakassova

Candidate of pedagogy, Associate-Professor, Al-Farabi Kazakh National University, Faculty of philosophy and political science, General and ethnic pedagogical Chair.

\section{Berdibaeva Sveta}

Doctor of Psychology, professor of department of general and ethnic psychology KazNU named after al-Farabi University. Email: berdybaeva_sveta@mail.ru

\author{
Aisaule Darkhanova \\ Senior Teacher of Pedagogical Sciences KazNPU after Abai. \\ Email:phd2014.kz@gmail.com
}

Doi:10.5901/mjss.2014.v5n20p2641

\section{Abstract}

The development of Kazakhstani society is presently at the stage where the life values held by the population are witnessing a transformation. Due to socio-economic difficulties, the importance of prestige and wealth is increasingly emphasized in the social value system. Against this background, the state has assumed the task of promoting a system of value orientation that reinforces national priorities: independence, social harmony, and patriotism. In this study, an analytical review of the literature revealed that the value orientation of individual ethnic and social groups is a vital strategic objective, as ideological orientations play a large role in the development of the ethnic identity of a nation. According to Yadov, values are system elements reflecting different levels in the structure of the social behavior of the individual. Within the system of reference points is a constant process of interaction and alignment of values. We consider it timely to recall in this context, the expression "Happiness is when a person is happy to go to work in the morning and happy to return in the evening."

Keywords: Value orientation, communication, culture, ethnicity, nation, regularities, landmarks 


\section{Introduction}

In the contemporary international community, the interaction of cultures is determined by the predicates of cultural globalization. Globalization has both positive and negative aspects. Its negative aspects are rooted in the possibility of losing cultural identity, which occurs as a result of acculturation and assimilation. Indeed, preservation of cultural identity in contemporary society is judged as the highest achievement of a civilization. Previously, however, cultural preservation was not valued, and one nation would devour another, dissolving the culture of the conquered people. [1]

Western globalization is manifested in the universality of human values and culture, which is expressed in the formation of uniform media, literature, art, movies and more. At the same time, the phenomenon of globalization has a common definition. For example, Professor Badi of the Paris Institute of Political Studies posits three dimensions of globalization that are considered important from the standpoint of international relations:

a) Globalization is a historical process that develops over many centuries.

b) Globalization means homogenization of people's lives worldwide under the same principles, commitment to common values, adherence to uniform customs and norms of behavior, and the desire to universalize everything.

c) Globalization is a recognition of growing interdependence, the main consequence of which is the undermining of national sovereignty under the pressure of new factors such as global firms, religious groups, and transnational management structures (networks) that interact on an equal footing not only among themselves but also with the states-the traditional actors of international relations. [2] The consequences of this aggression are a homogenization of the world; the intention to arrange people's lives according to one principle, common values, customs and norms of behavior; and the desire to universalize everything, including the ethnic cultural values inherent in a particular ethnic group, which are components of a culture of peace.

It is also important to remember that cultural globalization is not an irreversible or inevitable process. Rather, it is a process that is actively created and brought to people. Today, the struggle for cultural identity has drawn entire countries, social groups, and individuals. The problem of cultural globalization, including the policy of this globalization, which is implemented by the people themselves in their own interests, was one of the topics discussed in the United Nation's Millennium Forum held at the UN Headquarters in New York. The forum was attended by representatives from over a thousand non-governmental organizations and civil society organizations from more than hundred countries.

Meanwhile, cultural achievements of the world can be further developed either through simple passive learning or in the form of innovation through selective assimilation. It is crucial in this case to adopt a value system that already exists in society and promote values of individuals in order to fulfill the functional role of a "filter" that does not allow the creation of a separate surrogate culture. The transition period of mixed states is accompanied by changes not only in the political economic spheres but also in the socio-psychological realm. Consequently, the hierarchy of value regulators changes.

The transformation of values and behaviors appropriate in the present situation is characterized by the phenomenon of reorientation. This process has both positive and negative sides. In a democratic society, the dignity of each individual is of paramount importance. However, this pits the dominant individualist against the collectivist interests. Currently, special importance is attached to the need for an in-depth study of the dynamics of changes in the orientations of a population. In this study, one of the tasks set before the investigators was to determine the hierarchy of values that presently prevail among the people of Kazakhstan in the primary context of the ethnicity of the respondents. For example, according to Garmaeva, awareness of ethnic identity and identification with a particular ethnic group affect family values and ethnic and cultural norms as well as inter-ethnic interactions with peers in adolescence. Adults definitely have an understanding and awareness of their ethnicity. [3]

\section{Results and Discussion}

From the results of a survey, a hierarchy of the basic value orientations in Kazakhstan was defined (Figure 1). 
Figure 1. The hierarchy of values in Kazakhstan

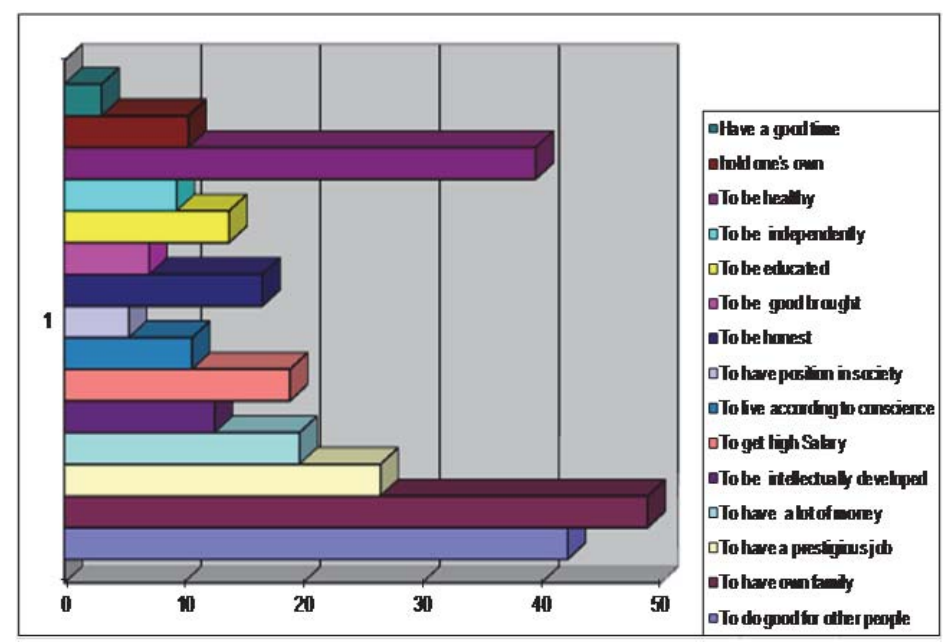

To the category of terminal values (i.e., values having the highest priority), the respondents attributed such attitudes as the following (in descending order): "to have a family," "to do good to people," and "to be healthy." The first two values are clearly rational in the deepest sense, and even metaphysical, and the third is likewise rational in any coordinate system.

Modern Western societies emphasize the intrinsic value of the individual. However, in Kazakhstan, 48.9\% of respondents believed that the main value in life is family. This idea was reported by both men and women: $48.4 \%$ and $49.8 \%$, respectively. The institution of family bears the main burden of passing on regulatory and socio-cultural values to the younger generation.

From a psychological viewpoint, this phenomenon can be explained as follows: Families provide a person with a sense of security, comfort, and being needed. This emotional security is especially important during periods of transformation in social relations such as when an individual witnesses a breakdown of the usual norms and values; changes social circles; struggles with unemployment; or is deprived of life's major necessities such as free medical care, low public utility costs, or free housing.

Economic reforms, accompanied by sharp changes in the social sphere, have increased personal responsibilities for men. In particular, marriage and earning a high income have gained importance because of the social benefits they provide and the presence of few workers in the family.

Some of them influence the priority of traditional values in determining national benchmarks. For example, natural languages reflect the culture and mentality of the people, present the national picture to the world, and represents the major moral and value systems of its ethnic groups. [4] In this study, it can be considered natural, then, that the highest ratio for the selection of this option (59.2\%) was among the residents of Kyzylorda region, where $98 \%$ of the population is of Kazakh ethnicity.

However, a different situation is presented in the capital, Astana, which scored the lowest in the country for traditional values. Astana is at the stage of dynamic development and construction, and social conditions here are not always conducive to marriage and family life (lack of time and suitable conditions for singles, high cost of housing, etc.). Another important factor is that the age composition of the population of Astana comprises significantly of the young, while the process of registration of marriage today is characterized by those in older age groups.

Further, according to the survey results, in the value system of Kazakhstan, moral and ethical standards of conduct hold a special place. Kazakhstan is a multi-ethnic state and has always been characterized by a tolerant attitude toward traditions, cultures, and customs of its various ethnic groups. Thus, it is logical that the category of terminal values includes the value of doing good to others (42.2\%). Lurie highlighted the subject of good and defined it as follows:

- Localization of the source of goodness, including the we-image and image of the patron

- Localization of the image of evil-an enemy

- Understanding of the mode of action, in which good triumphs over evil [5]

Throughout history, representatives of the Kazakh ethnic group have demonstrated their hospitality, kindness, and goodwill. 
Table 1

\begin{tabular}{|c|c|c|c|}
\hline Values & \multicolumn{3}{|c|}{ Nationality } \\
\hline \multirow{2}{*}{ To do good for people } & kazakh & Russian & Others \\
\cline { 2 - 4 } & $44.9 \%$ & $38.5 \%$ & $38.2 \%$ \\
\hline
\end{tabular}

Not surprisingly, for the Kazakhs, the value of doing good to others is dominant. It is particularly characteristic of the border regions, where population density is high and ethnic groups are varied: National Unity, Aktobe, and the South Kazakhstan region. The predominant ethnic group in these areas is Kazakh, comprising $78.7 \%, 70.7 \%$, and $67.8 \%$ of the regional population, respectively.

The importance of this terminal value for the people of Kazakhstan is particularly relevant at a time when contemporary reality characterizes the presence of ethically volatile "hot spots" in the Commonwealth of Independent States, especially the states bordering Kazakhstan.

In terms of quality, values are generally divided into two groups: the declared and real. One of the main declared priorities of the national strategy (Kazakhstan-2030), is "promoting a healthy lifestyle," and the slogan "Today it is fashionable to be healthy" is a favorite. In keeping with this trend, $39.5 \%$ of respondents reported that one of their important life values is personal health.

The importance of this value is objectively determined because the most prominent indicator of a transition economy is a poorly developed social sphere. The nation is witnessing the consequences-the deterioration of the nation's health, increased mortality, and a sharp decline in life expectancy.

In recent years, the population of Kazakhstan decreased by almost 1.5 million people. The reasons for this are not only intense migratory processes but also a reduction in the natural population growth. An increase in the value of health is most pronounced in regions with poor environmental conditions.

Figure 2. Region-wise value of health
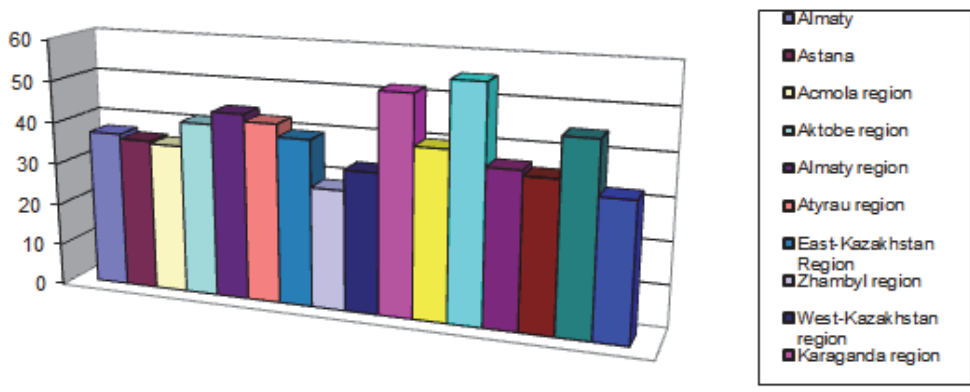

Personal health was named more frequently as a life value by residents of Kyzylorda (55.3\%) and Karaganda (51.8\%). The process of forming a healthy lifestyle should occur consciously, and therefore it should rely on scientifically sound criteria established using an effective, differentiated individual approach that is developed through methods of behavioral science.

These methods are based on the knowledge of the psychological and behavioral characteristics of the various social strata of a population. An analysis of the survey data revealed the following patterns: Women are more attentive to their health than are men. Health issues are the most relevant for the older generation owing to their age and the high cost of medical care.

The younger generations' benchmark of health is defined in the category of terminal. According to doctors' observations, children suffer more than those in other age groups due to various allergies and weak immune systems. However, we must recognize that a healthy lifestyle is highly valued by the current generation.

The lowest coefficient value of health, $26.5 \%$ (average $=39.8 \%$ ), was found for professional groups who identified themselves as police officers, judges, prosecutors, and national security personnel. This may be because good health is the prerequisite for these professions.

Viewing the regulative "health" from the national perspective, we observe the following: The coefficient value is 
lower (37.2\%) for Kazakhs than for Russians (42.4\%) and representatives of other nationalities (43.6\%). Traditionally, the value of health is not very high among the Kazakhs. In contrast, for Russians and other ethnic groups, it is the dominant character.

In addition, the overall hierarchy of values includes the value of prestige in the terminal category. The respondents identified the priorities such as "to have a prestigious job" and "to earn a high salary" to be related to social prestige. Here we are apparently dealing with another manifestation of the rational, which has the character of a practical, pragmatic, everyday value.

Work, among the other life values, holds a position of primary importance. Employment, related economic security, and social status play a significant role in people's lives. Among the respondent-suggested rubricator values, "to have a prestigious job" was one of the leading categories. The predicate of prestige in modern conditions strongly determines the value orientation of the motives and behavior in the field of cultural development. Thus, this value has implications for how one spends one's free time (e.g., visiting cafes, casinos, restaurants), suggesting a high material and social status.

In this context, professional identity is highly important. For farmers and farm workers, this value has no special significance (5.6\%). Instead, they place importance on the love for his native land and the desire to work hard for one's family. On the other hand, having a prestigious job is a highly ranked value orientation for the police, judges, prosecutors, and national security officers (37.2\%). Law enforcement employees have always had a high social status, and in recent years, the legal profession has clearly become one of the most prestigious among young people.

The career choice of today's young people is guided to a greater degree by the prestige factor. Job prestige implies a high social status and corresponding position of privilege. With age, the significance of this guide reduces.

This reduction is due to several reasons, including the impact that the development of the national strategy has on education and the environment, and the different values that have prevailed in a person's life over the years. A change is in process in Kazakhstan based on the orientation of factors (e.g., family, health) that determine vital functions of the individual. On the other hand, regulative behavior of the older generation was formed in an era when any type of work was held in high esteem.

Modern professional orientation of work among the younger generation emphasizes commercialization and going to other nations for studying. This entails a limitation in the choice of one's specialty, and results in a large number of workers traveling abroad in order to implement this requirement.

By valuing prestigious jobs, respondents are seeking not only a guaranteed social status but also financial abundance. For $19.7 \%$ of respondents, "to have a lot of money" was a primary value.

This guide can be explained by the decline in production, which led to an increase in unemployment and decrease in social transfers, inflation, and rising prices. This value orientation is thus characteristic of the mentality of a person living in a free market and widespread low income. For example, if the average monthly income and prices for food and other vital goods equalize each other, the population may not feel the lack of money so acutely.

The socialist idea that big money cannot earn an honest way of life left an imprint on the value system of the older generation. For example, it influenced their choice to live from paycheck to paycheck without seeking to acquire greater savings or wealth.

For members of a relatively new strata-the owners (in particular, farmers and entrepreneurs)-the presence of this guide is of great importance (50\% and $32.3 \%$, respectively). Clearly, this importance results from the fact that the availability of equity capital guarantees future business development.

Among the benchmarks of the current general system in Kazakhstan, a tendency is seen to increase the total index of wealth. People consciously respond to new economic relations within the nation and subconsciously change their ideas of life values.

For $18.9 \%$ of the respondents, an important factor in the value of health is to obtain higher wages. According to the statistics agency, $74 \%$ of Kazakhs are salaried workers. Despite such high importance of salary for the population, for the majority, it is insufficient to meet the cost of living.

In today's economic reality, a significant gap exists between the per capita income level and the cost of consumer basket, with the rise in prices for consumer goods and utilities exceeding the wage growth.

According to this parameter, nationwide results vary greatly: from 13.1\% (Pavlodar region) to 31.8\% (Akmola). In our view, income is directly dependent on the degree of profitability of the industrial production. The Pavlodar region abounds in refineries, and the majority of population here comprises of paid workers in these refineries. On the other hand, regions where agriculture is predominant are facing crisis throughout the country. To talk about wages in the state agricultural enterprises is almost unnecessary.

From the survey responses, we can see that there is a noticeable imbalance between earnings and expenditures not only for the unemployed and housewives but also for military personnel (30.0\%). This is because several years ago, 
military personnel lost their special benefits and privileges. If this trend continues, much of the population will experience symptoms of the states of the third world, characterized by economic insecurity.

The values of patriotism and national dignity and sovereignty have been subjected to considerable erosion, which, in part, influences the shaping of the cultural environment of the state. In recent years, scientific publications have suggested that issues concerning safe and sustainable future of a civilization are closely linked with its state of the spiritual culture, value systems, and priorities.

According to experts such as Romanovich and Ursula, the spiritual culture of modern society is in deep crisis, which is the main cause of the major global problems of today, and any further development of this state of crisis will become a real threat to the survival and development of civilization. [6]

Society and its culture harmoniously and sustainably develop to comply with the constant balance between spiritual and material values, which complement each other. The ratio of these two values in Kazakhstan's society is presented in Figure 3.

Figure 3. Proportion of Kazakhstani people reporting spiritual and material values as life priorities

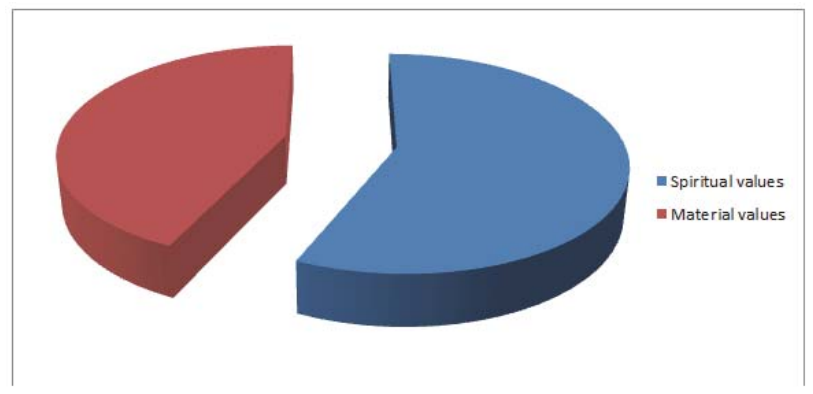

As the figure shows, the predominant values held by Kazakhstan's people largely pertain to spirituality. These include the traditional values of honesty, education, and preservation of dignity. The hierarchy of spiritual values is shown in Figure 4.

Figure 4. Hierarchy of spiritual values

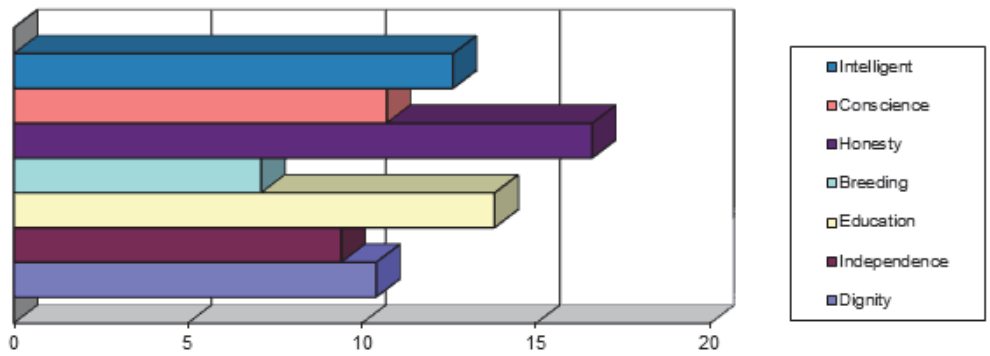

From these available options, we attempt to build a psychological portrait of the citizens of Kazakhstan. This portrait is characterized by high morality but a low level of value of good upbringing in the value system. Education should be imparted through the humanization of society and the revival of human values in the individual.

When the situation is assessed in terms of rationality, then at the first glance, the dominance of morality over good upbringing makes the people of Kazakhstan insufficiently rational in terms of, say, Western rationalism. However, if we consider the same situation from the standpoint of the interests of society, the state, and the future, then a healthy moral foundation and preservation of traditional values and customs will, lead to cultivating knowledge about good manners and etiquette, even if they are not rational enough.

Well-organized leisure activities play an important role in determining the cultural level of both society and individual. Socio-economic issues have created changes in the priority of values. At present, few people value having a good time (3.1\%), and they generally report their leisure preferences as discos, nightclubs, cafes, gaming, and 
entertainment centers.

Visits to libraries and theaters are parts of the cultural preferences of people who focus on spiritual values: education (26.5\%), education (26.1\%), and honesty (25.7\%). One recent, notable trend in the leisure preferences of the population is the growing interest in religion. The probable reasons for this phenomenon are a general feeling of disappointment, lack of self-confidence, and doubts about the future. It is well known that human consciousness has an inherent and continued need for faith.

In a modern society characterized by the dominance of mass culture, leisure, entertainment, and a primitive set of values, boundaries between socio-cultural groups become blurred. For example, the youth subculture has been introduced to behaviors that are not age appropriate (e.g., violence, brutality).

Taking into account the previous analysis, we can conclude that human values have a significant impact on the system of social relations in Kazakhstan. Socio-economic changes taking place in the country have resulted in certain changes in the nation's value system.

Thus, although the respondents attributed having a family, doing good to others, and being healthy to the category of the traditional life values, economic instability has led to a wider preference to the category of prestige, which includes having a prestigious job, high salary, and abundant money.

\section{Conclusion}

Environmental conditions change the priority of the regulators of individual behavior. Presently, the priority all values in the spiritual category, such as education, honesty, and independence, remains high and relevant, although they are slightly pushed into the background.

Therefore, at the present stage of social and cultural development of the state, the task is to form a system of values and guidelines and establish authorities that reinforce national priorities primarily on the basis of the society's spiritual values. Only the diversity of life goals will help build a harmonious unity among all social groups.

The national priorities should be based on common values, respect for personal dignity, recognition of the cultural identity of each ethnicity living in the country, the country's collective cultural identity, and the liberation of consciousness from intolerance and dogma. The basis of value orientations and ethnic prejudice is the process of finding a meaning (Jakupov).

Value orientations are the result of the process of finding a meaning, and ethnic prejudices are the result of his procedural expression or condition. Thus, both values and ethnic prejudice are the elements of the system structure of the ethnic identity card (Soldatova).

Thus, the analysis of Kazakhstani values shows that they can be characterized as being localized in the semantic field of "rational." Further, the rational self has no unambiguous interpretation but rather a whole range of rationalities with different ethics, values, and meanings.

\section{References}

Kravchenko A. Cultural studies: Textbook for Universities. 3rd ed. Moscow: Academic Project. 2001.

Lebedeva M.M. World politics and international relations at the turn of the millennium, 2000 and N.A Baranov. Political relations and the political process in modern Russia: A course of lectures. 2011

Garmaeva T.V. Ethnic identity peculiarities in primary schoolers and teenagers of different nationalities who live in a megacity (in Russian). Psikhologicheskie Issledovaniya, 2010, 2(10)

Gimaev J.A. Conceptual component of the "beauty of the homeland" in the structure of the concept of HOMELAND (on the example of school texts in literature) Bulletin MGOU. A series of "Russian Philology." No. 2. 2010. Moscow: Izd MGOU. pp.73-77.

Lurie S. Metamorphoses of traditional consciousness. Theoretical basis of ethnopsychology and its use for analysis of historic and ethnographic materials? St. Petersburg., 1994. p.142

Romanovich A.L., Ursula A.D. Sustainable future (globalization, security, noosphere Genesis) (in Russian). Moscow: "LIFE" Pub. Group. 2006. p.512 